\title{
A New Look at an Old Canal
}

\author{
Assaf Marom, M.D., Ph.D. ${ }^{1}$
}

\section{ABSTRACT}

Attempts to explain abducens vulnerability have centered around the petroclival segment of its pathway in the skull base, in particular, its relations to the Dorello's canal and the petrosphenoidal ligament of Grüber. This study aims to contribute to the definition of the Dorello's canal and to the understanding of abducens vulnerability from an evolutionary perspective. The petroclival region and the Dorello's canal in particular were examined in a sample of 86 primate skulls. The sample contains 20 Pan troglodytes (common chimpanzee), 35 Gorilla gorilla, 20 Pongo pygmaeus (orangoutan), and 11 Hylobates moloch (gibbon) skulls. Distance between the petrous apex and tip of the posterior clinoid process was measured using a $10-\mathrm{mm}$ scale that was inserted into the endocranium. Complete absence of the Grüber ligament and an uninterrupted osseous circumference of the Dorello's canal (foramen) was demonstrated in all nonhuman primate species. Whatever the reason for the morphological difference between the human and ape Dorello's canal, it is without a doubt suggestive of the source of vulnerability of the abducens nerve, as the ligament of Grüber, unique to the human configuration, renders the contents of the Dorello's canal susceptible to compression against the cranial base.

KEYWORDS: Abducens nerve, petrosphenoidal ligament, petrosphenoidal canal, skull base

General somatic efferent axons of the abducens (abducent) nerve (sixth cranial nerve) originate in the abducens nucleus, which occupies a paramedian position in the somatic motor column of the caudal pons. Its fibers pass anteriorly through the tegmentum of the pons and emerge from the pontomedullary sulcus lateral to the pyramids to enter the pontine cistern of the subarachnoid space (cisternal segment). ${ }^{1}$ Here one or more rootlets unite to form the single trunk of the nerve, which shortly thereafter pierces the dura mater at the clivus of the occipital bone; in due course, the nerve runs toward the superior orbital fissure in the epidural space. ${ }^{1,2}$ In fact, it was suggested that the cisternal segment extends further than the point where the dura is pierced, as arachnoid matter has been demonstrated to envelope the nerve and cerebrospinal fluid to occupy the subarachnoid space of this arachnoid "sleeve."

The intracranial epidural part of the nerve, which is in the petroclival area (petroclival segment) and then in the cavernous sinus (cavernous segment), has drawn the attention of anatomists, neurologists, and neurosurgeons over the past century. Interest increased in light of advances in skull base surgery and the lack of unequivocal definitions in the regional microanatomy, which are of key importance in interpretation of clinical scenarios involving the sixth nerve. ${ }^{4,5}$ Additionally, it was the exceptional susceptibility to injury of this nerve among the cranial nerves, which mediate ocular motility, that has encouraged further studies,
${ }^{1}$ Department of Anatomy and Anthropology, Tel-Aviv University, Tel-Aviv, Israel.

Address for correspondence and reprint requests: Assaf Marom, M.D., Ph.D., Department of Anatomy and Anthropology, Sackler Faculty of Medicine, Tel-Aviv University, Ramat-Aviv 69978, Tel-Aviv, Israel (e-mail: assafma@post.tau.ac.il).

Skull Base 2011;21:53-58. Copyright (C) 2011 by Thieme Medical
Publishers, Inc., 333 Seventh Avenue, New York, NY 10001, USA. Tel: +1 (212) 584-4662.

Received: February 20, 2010. Accepted: May 25, 2010. Published online: August 6, 2010.

DOI: http://dx.doi.org/10.1055/s-0030-1263282.

ISSN 1531-5010. 
almost all of which concluded that abducens vulnerability should be viewed as stemming from its long intracranial course. In an attempt to question the myth of the abducens intracranial length, it was compared with that of the trochlear nerve and was found to be shorter; the author of this research advocates the abducens local anatomic relations rather than length as reasons for its vulnerability. ${ }^{4}$

The present study focuses on the petroclival segment of the sixth nerve, where it traverses the apex of the petrous element of the temporal bone in passing from the posterior cranial fossa to the middle cranial fossa. Can the anatomy of this pathway provide a clue to the source of the abducens vulnerability?

The intriguing anatomy of this region was studied as early as 1859; Grüber first gave a descriptive account of the relations of this segment of the nerve, in particular to a ligament that stretches between the petrous apex (spine of petrous) and the accessory clinoid process of the sphenoid bone. ${ }^{6} \mathrm{He}$ defined it as the sphenopetrosal ligament, hence, in later publications, it is often referred to as the ligament of Grüber. ${ }^{2,5}$ According to his observations, the ligament forms the superior border of the sphenopetrosal passageway to the abducens nerve as well as to the inferior petrosal sinus. This opening is interestingly named after P. Dorello, whose exploration of this region took place later. ${ }^{7} \mathrm{He}$ first defines the junction between the petrous apex and the posterior clinoid process of the sphenoid as an "insenatura ossea colla concavita" (p. 213), namely an osseous concavity. He then explains that the sphenopetrosal ligament of Grüber bridges the concavity, thereby forming an osteofibrous canal for the sixth nerve. In his view, compression of the nerve at its passage through the canal may be held responsible for cases of paralysis: "io credo che la paralisi del nervo abducente . . . sia dovuta frequentemente a compressione di esso durante il suo passagio sotto il ligamento petrosfenoidale" (p. 217). Several studies followed, ${ }^{2,8}$ but it was not until 1991 that the first microanatomic report of this area was published, introducing the controversies surrounding the relations of the nerve to the canal and to other structures that had not been considered before (e.g., the inferior petrosal sinus). ${ }^{9}$ Later attempts aimed to redefine Dorello's canal and its contents and to measure its boundaries, in particular Grüber's ligament, which was found to be $11.53 \mathrm{~mm}$ long on average. ${ }^{5}$ Although the literature reviewed here recommends looking for new considerations of the abducens enigma in its convoluted microanatomy and relations, the present study explores the evolutionary history of these relations. Data regarding the anatomy of the petroclival region in great apes have not been considered thus far. It is my contention that an evolutionary perspective on Dorello's canal can shed new light on our understanding of abducens vulnerability in human.

\section{METHODS}

The space bounded between the petrous apex (petrosal spine) posterolaterally, the accessory clinoid process anteromedially, and the osseous concavity of the petroclival junction inferiorly was carefully examined in a sample of 86 primate skulls of the Adolph Schultz collection at the University of Zurich. The sample contains 20 Pan troglodytes (common chimpanzee), 35 Gorilla gorilla, 20 Pongo pygmaeus (orangutan), and 11 Hylobates moloch (gibbon) skulls—all of both sexes. View of the petroclival region was achieved by using a frontfacing mirror, which was inserted into the endocranial cavity via the foramen magnum, providing a posterolateral view of the petroclival region. The distance between the petrous apex and the tip of the posterior clinoid process was measured using a $10-\mathrm{mm}$ scale that was inserted into the endocranium. This distance approximates the length of Grüber's ligament, as it stretches between these two structures. ${ }^{6}$ Data on the morphology of Dorello's canal and Gruber's ligament in humans were obtained from the literature. , $^{2,8}$

\section{RESULTS}

All four primate samples confirmed the following configuration: Dorello's canal in primates is actually a rounded foramen that occupies the petroclival space. This opening is bounded inferiorly by the petroclival concavity and superiorly by the union of the petrosal spine and the accessory clinoid process, as the distance between these elements was $0 \mathrm{~mm}$ (fused variant) in 40\% of the skulls, $1 \mathrm{~mm}$ (or less) in $43 \%$ of the skulls, and $2 \mathrm{~mm}$ (or less) in 9\% of the sample (Figs. 1 and 2). In $15 \%$ of the fused variants, the contact (suture) between the two osseous elements was completely indiscernible. In all skulls, the groove for the inferior petrosal sinus was clearly seen running between the canal and the jugular foramen. This venous sinus drains from the cavernous sinus into the sigmoid sinus and internal jugular vein, ${ }^{1}$ and its ostium is reported to be part of the contents of Dorello's canal. $^{5}$

\section{DISCUSSION}

Although Dorello's canal in modern humans is an osteofibrous structure and elliptical in shape, as indicated by the differences between its larger horizontal axis (diameter) and superior-inferior axis, ${ }^{5}$ in primates it is a roundish osseous opening, closed superiorly by the fused petrosal spine and accessory clinoid process (Fig. 3).

In my view, these fundamental differences between the primate and human configurations are the source of the abducens vulnerability; changes in the anatomy of the cranial base during the course of human evolution-stemming possibly from the increase in endocranial capacity - have brought about the distancing 

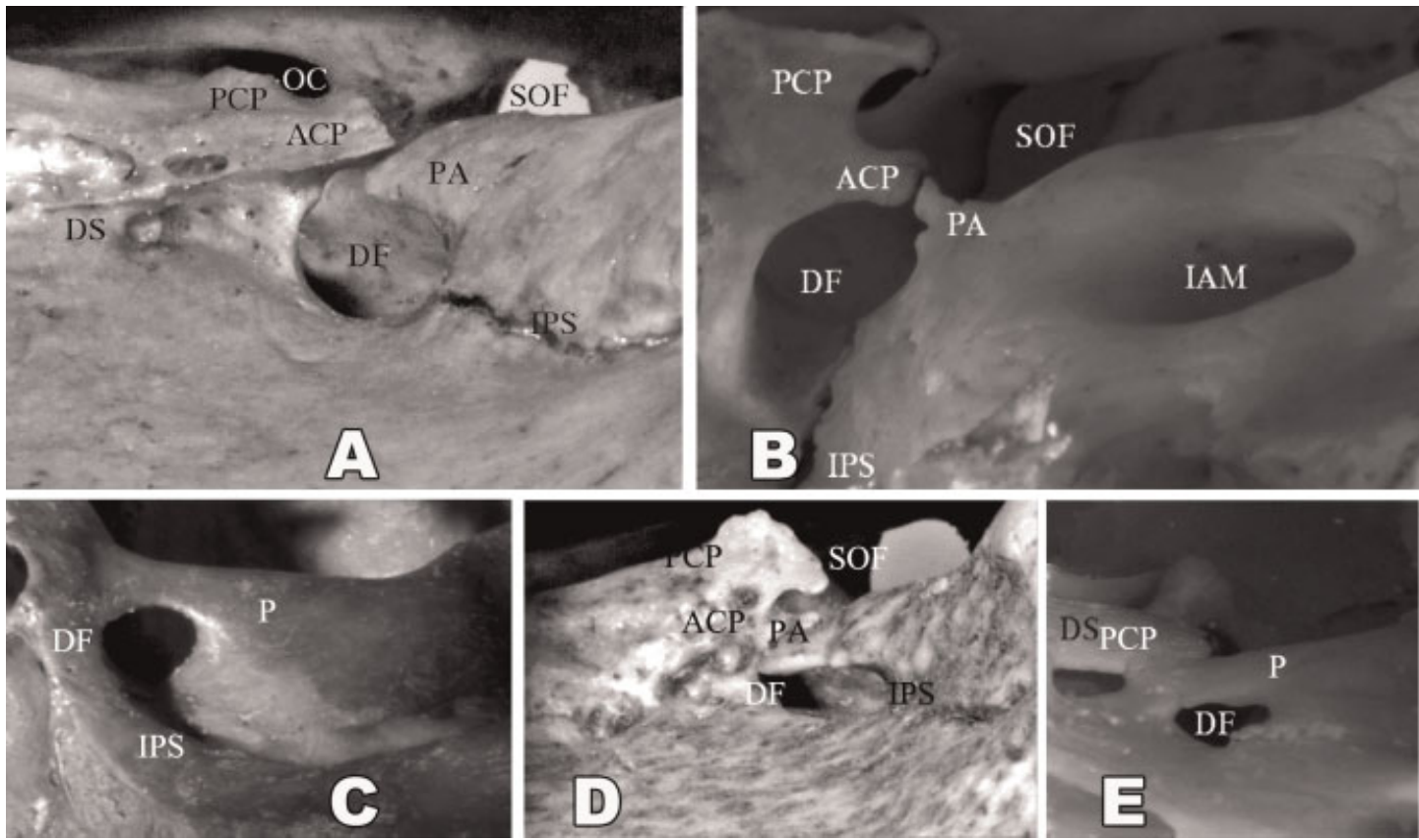

Figure 1 Posteromedial views of the right petroclival region in (a) Gorilla gorilla, (b) Pongo pygmaeus, (c) Hylobates moloch, and $(d, e)$ Pan troglodytes, demonstrating the osseous superior border of the Dorello foramen (DF), formed posterolaterally by the petrous apex (PA) and anteromedially by the accessory clinoid process (ACP). Note the relation of the groove for the inferior petrousal sinus (IPS) to this foramen. DS, dorsum sella; IAM, internal acoustic meatus; OC, optic canal; P, petrous part of temporal bone; PCP, posterior clinoid process; SOF, superior orbital fissure.

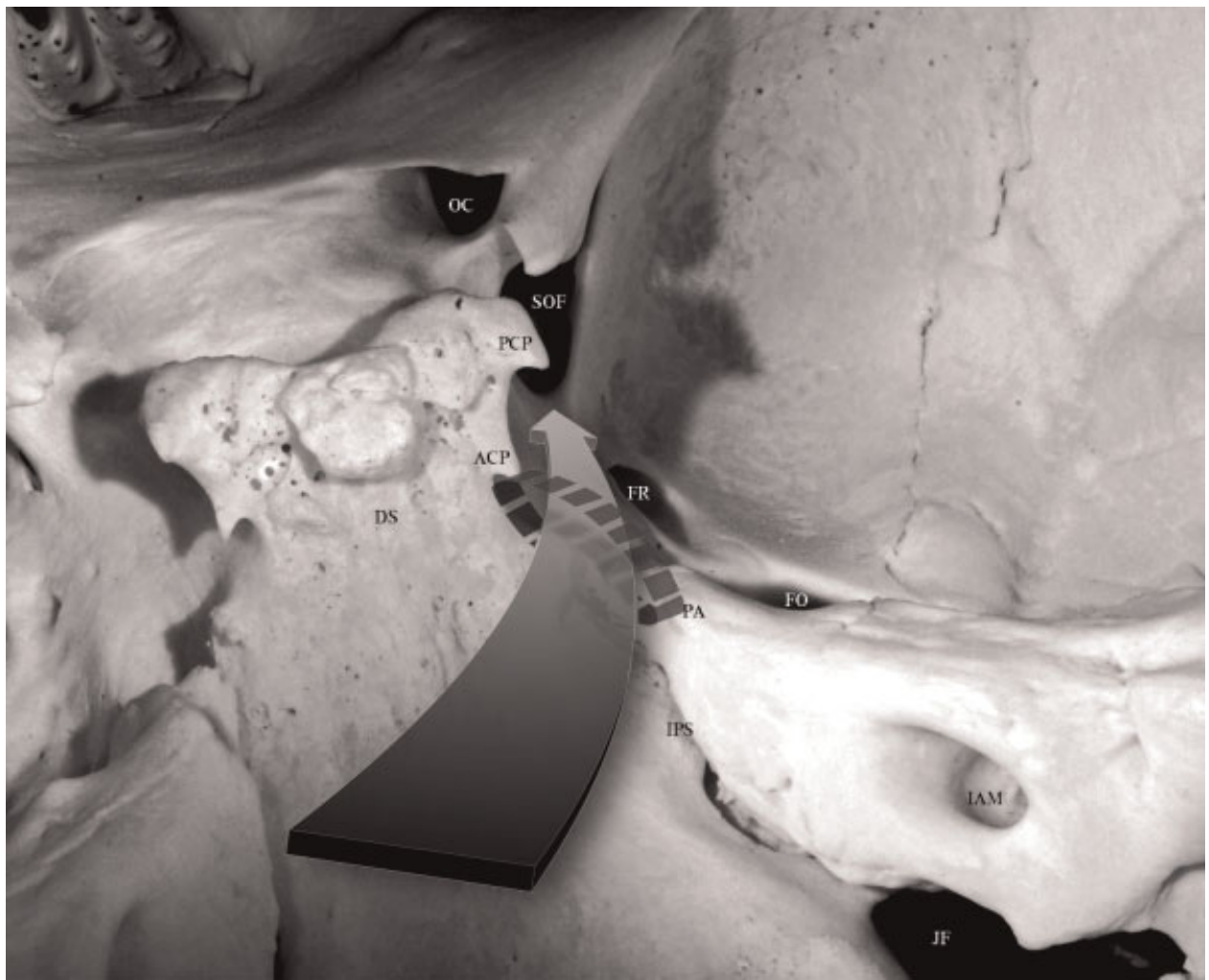

Figure 2 A posteromedial view of the petroclival region in the modern human cranial base. The osseous insertion sites for the petroclival ligament of Grüber, namely the accessory clinoid process (ACP) and the petrous apex (PA), are indicated, and the space (elliptical in shape) between them is depicted. An arrow passing through Dorello's canal indicates the route of the abducens nerve to the superior orbital fissure (SOF). DS, dorsum sella; FO, foramen ovale; FR, foramen rotundum; IAM, internal acoustic meatus; IPS, inferior petrousal sinus; JF, jugular foramen; OC, optic canal; PCP, posterior clinoid process;. 


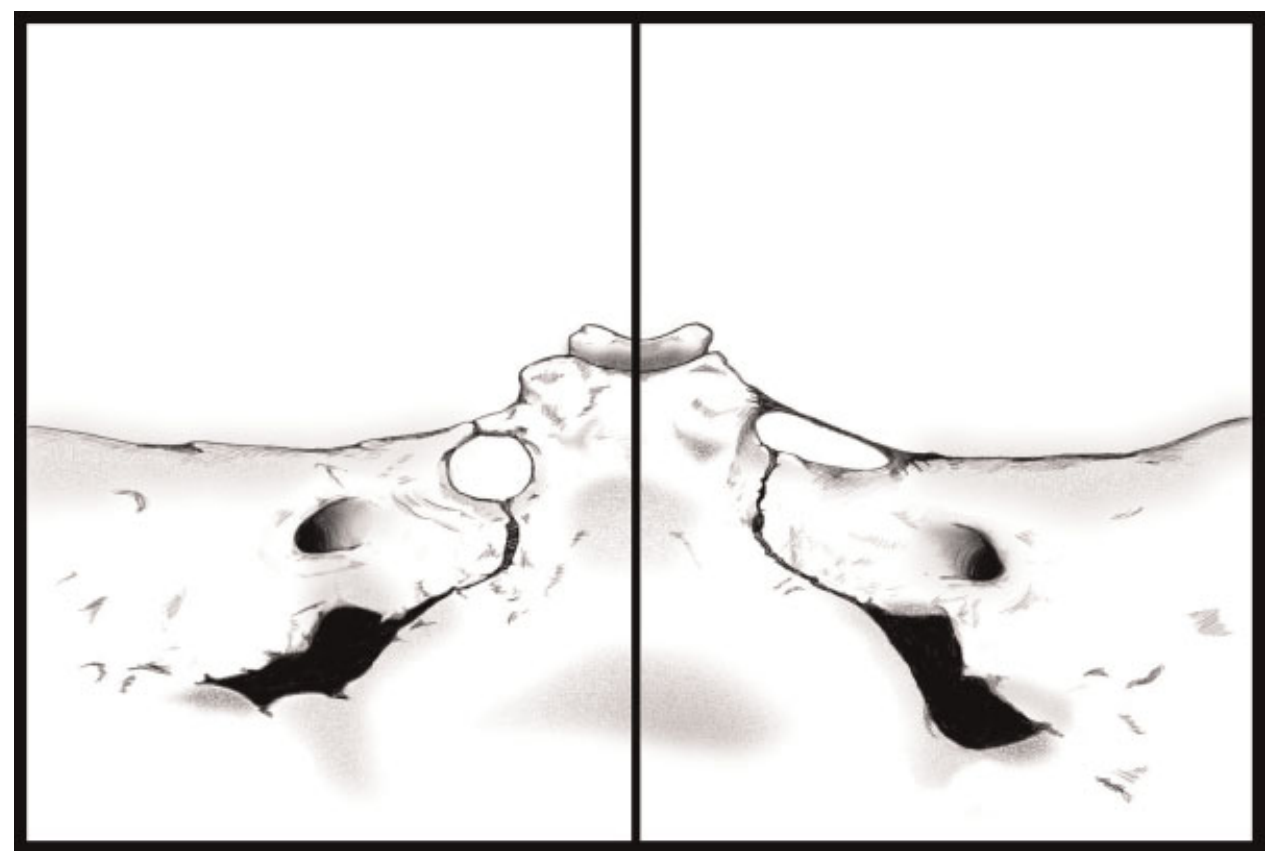

Figure 3 A schematic posterior view of the petroclival region in a modern human (right) and an ape (left). Note that although the human Dorello's canal is an osteofibrous structure, bounded superiorly by the ligament of Grüber, the fusion of two osseous elements forms the roof of the canal in apes. See text for further details.

of the dorsum sella and the petrous apex, thereby elongating the horizontal axis (diameter) of Dorello's canal and causing the discontinuity of its osseous perimeter. It was also for this reason that the sphenopetrosal ligament of Grüber replaced the bony bridge and Dorello's canal became an osteofibrous structure, rendering its contents susceptible to compression against the cranial base. Other differences in the regional morphology have been demonstrated ${ }^{10}$ and pertain to the crescent of foramina and in particular to the shape of the spacious superior orbital fissure; in humans, it is an elongated, comma-shaped fissure that narrows laterally, and the African apes exhibit a round and confined foramen. Whatever the cause of this difference, it is not inconceivable that the reasons may be along the same lines as for the petroclival region, namely, the changes may be seen as morphological consequences of increasing endocranial volume.

Returning to the functional anatomy of the petroclival region, a bony sphenopetrosal bridge is far more advantageous than a fibrous one, as deformation inflicted on a ligament by intracranial masses, for instance, would be greater. Not only is the ligament more elastic, but the fact that it has an hourglass shape, with its wide distal insertions narrowing toward its center, ${ }^{5}$ brings the distribution of stresses on the ligament to be the greatest in its middle third. This observation is of particular importance in humans in light of the fact that in 15\% of people, the abducens nerve was found to occupy the middle third of Dorello's canal. ${ }^{5}$ The mere fact that the petrous is indented is advantageous not only due to the mechanical protection it provides to its contents, but also because the indentation reduces the sharpness of the angle in its course $^{3}$ by truncating it. For this reason, preservation of a canal during the course of human evolution, as it shaped the human cranial base, was favorable. In this sense, vulnerability of the abducens nerve is not enigmatic; as brain size appears to be a major determinant of basicranial variation, especially the angle of the cranial base in the midsagittal plane, ${ }^{11}$ it is suggested that the change in endocranial capacity influenced the morphology of the cranial base in a way that preserving the sphenopetrosal foramen of great apes in the form of the human Dorello's canal necessitated the formation of a fibrous bridge, namely Grüber's ligament, and this came with a costincreased abducens vulnerability.

Putting my thesis to a test is admittedly not an easy task; however, it may be examined through its possible clinical implications. First, I propose that apes are considerably less prone to abducens neuropathies resulting from compression of the nerve than humans, as the nerve is protected by an osseous canal. Second, ossification of Grüber's ligament was observed in $10 \%$ of humans. ${ }^{5}$ In accordance with my prediction, these individuals will benefit from the same protective effect of Dorello's canal as the apes.

\section{ACKNOWLEDGMENTS}

I am indebted to Professor Yoel Rak from the Department of Anatomy \& Anthropology at Tel Aviv University and to Professor Ron Shahar from the Department 
of Surgery at the Hebrew University for helpful discussions and for reading the manuscript and making important comments. Observations on the ape specimens were performed at the Department of Anthropology of Zurich University, in Zurich, Switzerland. With much gratitude, I acknowledge the permission to examine the specimens granted to me by Professor Christoph Zollikofer and Dr. Marcia Ponce De León. Finally, I wish to thank Mrs. Avishag Ginzburg for her help from the outset of this study and Mr. Eran Cohen, who skillfully performed the artwork.

\section{REFERENCES}

1. Standring S. Gray's Anatomy. 39th ed. Edinburgh: Elsevier Churchill Livingstone; 2005:337-340

2. Nathan H, Ouaknine G, Kosary IZ. The abducens nerve. Anatomical variations in its course. J Neurosurg 1974;41: 561-566

3. Ono K, Arai H, Endo T, et al. Detailed MR imaging anatomy of the abducent nerve: evagination of CSF into Dorello canal. AJNR Am J Neuroradiol 2004;25:623-626
4. Hanson RA, Ghosh S, Gonzalez-Gomez I, Levy ML, Gilles FH. Abducens length and vulnerability? Neurology 2004;62: 33-36

5. Tsitsopoulos PD, Tsonidis CA, Petsas GP, Hadjiioannou PN, Njau SN, Anagnostopoulos IV. Microsurgical study of the Dorello's canal. Skull Base Surg 1996;6:181-185

6. Grüber W. Beitrage zur anatomie des keilbeins und schlafenbeins. In: Richter HE, Winter A, eds. Schmidt's Jahrbucher der in-und Auslandischen. Gessamten Medicin, Anatomie und Physiologie. Leipzig: Verlag Von Otto Wigard 1859:40-41

7. Dorello P. Considerazioni sopra la causa della paralisi transitoria dell' abducente nelle flogosi dell' orecchio medio. In: Ferrari G, ed. Atti della Clinica Oto-Rino-Laringoiatrica. Roma: Tipografia del Campidoglio; 1905: 209-217

8. Vail RL. Anatomical studies of Dorello's canal. Laryngoscope 1922;32:569-575

9. Umansky F, Elidan J, Valarezo A. Dorello's canal: a microanatomical study. J Neurosurg 1991;75:294-298

10. Rak Y, Kimbel WH, Johanson DC. The crescent of foramina in Australopithecus afarensis and other early hominids. Am J Phys Anthropol 1996;101:93-99

11. Lieberman DE, Ross CF, Ravosa MJ. The primate cranial base: ontogeny, function and integration. Yearb Phys Anthropol 2000b;43:117-169 